\title{
SPATIAL DISAGGREGATION OF THE BIOENERGY POTENTIAL FROM CROP RESIDUES USING GEOSPATIAL TECHNIQUE
}

\author{
Abhishek Chakraborty*, Anima Biswal, Varun Pandey, C S Murthy, P V N Rao, S Chowdhury \\ Agricultural Sciences \& Applications, Remote Sensing Applications Area \\ National Remote Sensing Centre, Indian Space Research Organization, Hyderabad, India
}

\section{Commission III, WG III/10}

KEY WORDS: Crop residue, biomass, bioenergy, spatial disaggregation, random forest, NPP

\begin{abstract}
:
Limited national fossil fuel resources and sustained increases in energy prices have resulted in nationwide efforts to study and deploy alternative energy sources. Despite high prospect, biomass resources has not been effectively utilized in India due to the lack of information on amount, type and time of its availability on a geospatial frame work to facilitate its transportability, establishment of bio-fuel plants tailor made for specific crop residues. Hence, a comprehensive approach towards geospatial mapping of bio-energy potential from surplus crop residues of selected crops (rice. wheat, cotton and sugarcane) over the Haryana state of India is implemented by utilizing a hybrid model combining both statistical and remote sensing technique. Bioenergy potential was calculated from crop production statistics collected at district level. The grain production data were converted into gross residue potential using residue production ratio. The crop residue was further converted into collectable crop residue using collectable coefficient. To generate the spatial map of the selected crops, potential crop masks were prepared using multi-temporal satellite data. These crop masks were then converted to crop fraction at $1 \mathrm{~km}$ grid level. MODIS NPP data product was then processed and converted into same $1 \mathrm{~km}$ to account the spatial variability of biomass potential. Using these crop fractions as independent variables, relationship was established with NPP as dependent variable using a machine learning technique (Random Forest algorithm). These crop specific response curves (crop fraction vs NPP) were utilized as a weight to disaggregate district level gross biomass potential to $1 \mathrm{~km}$ grid level. The spatial map thus generated provided spatial details of the type and amount surplus crop residues and could be vital input for planning and policy making of utilization of the surplus biomass resources of India.
\end{abstract}

\section{Introduction:}

Energy is the fundamental need of human beings with air, water, shelter and food (energy). Improving living standard, economic and industrial expansions, population growth has possess serious challenges on India's energy sector. Although the country is recognized as one of fastest growing economies of the world, basic energy needs of thousands of millions of its citizens are yet to be fulfilled. It is reported that by 2031-2032, power generation capacity must increase to nearly $800 \mathrm{GW}$ from the current capacity of around $183 \mathrm{GW}$, inclusive of all captive plants to meet the basic energy needs of its citizens (world bank report, 2011). Taking a historical prospective, Kumar and Jain, 2010 reported that during $1970-71$ to 2006-07, coal consumption in India has increased from 71.2MT to 462.7MT, crude petroleum consumption has gone up from 18.4MT to $146.5 \mathrm{MT}$ and the natural gas consumption rose from 0.64 Giga cubic meters (GCM) to 31.36 GCM. Similarly, electricity consumption has also increased from a level of 43.7 TWh to 443.1 TWh during the same period.

Growing energy demand coupled with limited conventional fuel options, geo-politics of oil and environmental concern has compelled India to search for renewable and sustainable energy options. Biomass resources are relatively uniformly available in India compared to other renewable sources. Realizing the potential of bioenergy generation, the Ministry of New and Renewable Energy (MNRE), India has initiated several biomass programs, with encouraging degree of success.

Agro-residues are geographically distributed with variation in spatio-temporal availability. For viable commissioning of biomass power plant, prior and precise database of residue distribution, seasonal fluctuation (peak and lean period of availability) is a pre-requisite. Logistics such as residue harvest, collection, storage, transportation are spatially interlinked and need meticulous planning. Adequacy, precision, reliability of data collected through traditional methods (survey or secondary data collection) for bioenergy planning is a matter of question, which often lead to over or under estimation of potentially accessible energy source. To resolve these constraints, high resolution spatial map of surplus biomass potential from the crop residues over India is pre-requisite. The present proposal is a comprehensive approach towards mapping of surplus biomass potential from crop residues of four major crops viz. kharif rice, wheat, cotton and sugarcane over Haryana state of India by describing a hybrid model which combines both statistical and remote sensing methods. Spatial map of surplus biomass from residue would further facilitate decision making in terms of site suitability of bioenergy plants.

\section{Methodology}

\subsection{Study area}

Haryana state is selected as a study area for the present research work. It is located between the $27^{0} 39^{\prime}$ to $30^{\circ} 55^{\prime} 05^{\prime \prime}$ North Latitudes and $74^{\circ} 27^{\prime} 08^{\prime \prime}$ to $77^{\circ} 36^{\prime} 05^{\prime \prime}$ East Longitudes. Geographically it is one of the smallest states of India spread over $44212 \mathrm{~km}^{2}$ area and accounts 1.37 percent of country's total area. Haryana is mainly a agrarian state, with diversified agriculture. It is mainly dominated by the wheat crop during rabi season; and rice, cotton and sugarcane during kharif season. As a result, Haryana generate lots of agriculture surplus residues, which they tend to burn to clear the field for the next crop. This causes lot of pollution in an around the state particularly over Delhi. So, there is a scope to divert these agricultural residues to generation of power and other purpose.

*Corresponding author: jeet.abhishek@gmail.com 
The pre-requisite for this is a spatial map of distribution of these agricultural residues across the state. In the present study, is an attempt to demonstrate the technique to assess the surplus crop residue at district level and then disaggregate it to $1 \mathrm{~km}$ grid level using remote sensing based proxies.

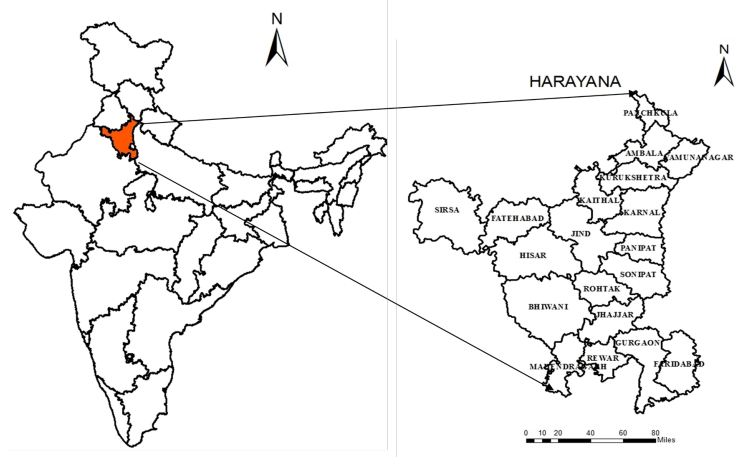

Figure 3.1 Area of the present study

\subsection{Analysis of district level crop statistics}

One of the most popular method to calculate the gross biomass of crop at district level is to use the district level crop statistic i.e. area, yield and production data. These data are available in the govt websites, particularly under the custody of department of economics and statistics.

\subsubsection{Analysis of district level crop production data}

Agricultural statistics are fundamental datasets for assessing the general conditions of agricultural production and rural economy in India and are proven to be reliable and useful by various applications. Crop Statistics of India, as available from the Ministry of Agriculture (MoA), Govt. Of India is a major data source for estimation of crop residue biomass availability (Directorate of Economics and statistics, 2016). The MoA has adopted a reliable and scientifically robust procedure to derive relatively precise estimation of crop production, cropping area, and yield. District wise crop production statistics of the selected crops i.e. kharif rice, wheat, cotton and sugarcane of Haryana state has been collected from the Directorate of Economics and statistics and used in the present study.

Crop residue is by-product of crop production system. Gross residue potential is the total amount of residue produced while surplus residue potential is the residue left after any competing uses (such as cattle feed, animal bedding, heating and cooking fuel, and organic fertilizer). The surplus fraction can be used for bioenergy generation. Standard procedure is followed to estimate the gross and surplus potential which are discussed below (Hiloidhari and Baruah, 2011a and 2011b).

Gross residue potential of a particular crop depends upon three parameters viz. (i) area covered by the crop (ii) yield of the crop, and (iii) Residue Production Ratio (RPR) value of the crop. Using these parameters, gross residue potential is estimated as follows:

$$
C R g(j)=\sum_{i=1}^{n} A(i, j) \times Y(i, j) \times R P R(i, j)
$$

where, $\operatorname{CRg}(\mathrm{j})$ is gross crop residue potential at $\mathrm{j}^{\text {th }}$ state from $\mathrm{n}$ number of crops, tonne; $A(i, j)$ is area under $i^{\text {th }}$ crop at $j^{\text {th }}$ state, ha; $Y(i, j)$ is yield of $i^{\text {th }}$ crop at $j^{\text {th }}$ state, tonne $h^{-1}$ and $\operatorname{RPR}(i, j)$ is residue production ratio of $i^{\text {th }}$ crop at $j^{\text {th }}$ state. The values of area and yield are taken from crop statistics data as stated earlier.
Crop residues have competing uses and therefore, only a certain portion of gross residue is available for energy purpose. This portion is termed as surplus and estimated as follows.

$$
C R s(j)=\sum_{i=1}^{n} C R g(i, j) \times S F(i, j)
$$

where, $\operatorname{CRs}(\mathrm{j})$ is surplus residue potential at $\mathrm{jth}$ state from $\mathrm{n}$ number of crops, tonne; $\operatorname{CRg}(i, j)$ is gross crop residue potential of ith crop at jth state, tonne and $\operatorname{SF}(\mathrm{i}, \mathrm{j})$ is surplus residue fraction of ith crop at jth state. In this study, data available from Biomass Resource Atlas of India (BRAI) is used to estimate surplus residue fraction i.e., SF(i,j) (Biomass atlas, 2004). Limited literatures are available on state and crop wise surplus residue potential in India except for few states. Therefore, BRAI reported values of gross and surplus residue are used in this study to estimate surplus residue fraction both at state and crop level. Bioenergy potential from crop residue biomass is estimated using the following expression:

$$
E(j)=\sum_{i=1}^{n} C R s(i, j) \times H V(i, j)
$$

Where, $E(j)$ is bioenergy potential of $n$ crops at $j^{\text {th }}$ state, MJ; CRs $(i, j)$ is surplus residue potential of $i^{\text {th }}$ crop at $j^{\text {th }}$ state, tonne; $\mathrm{HV}(\mathrm{i}, \mathrm{j})$ is heating value of $\mathrm{i}^{\text {th }}$ crop at $\mathrm{j}^{\text {th }}$ state, MJ tonne $\mathrm{e}^{-1}$. Ignoring the spatial variation, heating values of residues considered in this study are taken from standard sources (Biomass Atlas, 2004)

\subsection{Analysis of the geospatial datasets}

The present study used different satellite and geospatial product to meet the objective of the study. A succinct description of the same is provided below;

\subsubsection{Land use and land cover (LULC) data}

National Remote Sensing Centre operationally assess national level LULC map on 1:250,000 scale using multi-temporal AWiFS data sets to provide on annual basis, net sown area for different cropping seasons and integrated LULC at the end of each year starting from 2004-05. In the present study, multi-year LULC data were used to generate potential agricultural area of Haryana state. The kharif only, rabi only, double/triple crop area and current fallow were clubbed to generate the potential agricultural area. This potential agriculture mask was further used to remove other areas such as non-agricultural areas and analysis was done over the agricultural areas only.

\subsubsection{Generation of the crop mask}

Multi-temporal satellite data were used to classify the selected crops over Haryana. Crop mask is the essential part of the spatial disaggregation of the district level biomass.

Kharif season is the main rice growing season of Haryana. During kharif season Haryana is always under persistent cloud cover. So availability of cloud free optical data during kharif season is very limited. Hence synthetic aperture radar (SAR) data was used to map kharif rice crop over Haryana. At least three RADARSAT-2 scenes were required during rice growing season i.e. July, August and September to map the rice crop. The SAR data contains an inherent speckle noise which makes it difficult to interpret the data. Gamma-MAP speckle filter with $5 \times 5$ window size has been used to reduce the speckle in the data. Further, the data has been converted to backscattering coefficient (sigma naught, $\sigma^{\circ}$ ). Three date temporal stack of the 
$\sigma^{\circ}$ images were created. The decision rules were defined based on the temporal backscatter profile of the rice crop. For rice crop, the backscatter is observed to be low during the puddling/transplantation stage due to specular reflection and the values were ranging from -18 to $-24 \mathrm{~dB}$ and gradually the backscatter increased after 24 days with increase in tillers and stems and during the third date the backscatter further increased with the increase in volume scattering. This unique backscatter response of the rice crop forms the basis for its accurate classification. Decision rule based classification of the kharif rice was performed using the RADASRSAT- 2 data. The overall accuracy was found to be more than $85 \%$. potential rice crop mask was prepared using multi-year rice crop map. It is observed that the rice crop is grow throughout the state but it is mainly concentrated over the kaithal, karnal, kurushetra districts.

Wheat crop is grown during rabi season in Haryana. The sowing starts during late October, it attains its peak vegetation stage during late January and early February, and harvested during late March or early April. Mustard, Pulses and vegetable crops are the main competing crop of wheat over Haryana. But the spectral signature of wheat and its length of the growing season is unique. So it could be easily identified using satellite data. Multi temporal NDVI data were prepared using the AWiFS satellite observation. The typical phenology of wheat was captured using the decision rule and wheat crop was mapped. District wise rules were prepared for wheat classification and mapped for wheat crop mask. The district level wheat area statistics were also consulted for verification along with the ground truth observations. The wheat crop map was found to have accuracy of more than $85 \%$.

Cotton crop is grown during the kharif season over Haryana. It is generally planted during June-July month and it attains its peak vegetation during September- October. The peaking of the cotton starts during November and goes upto January. Due overcast condition optical data is not available during June to September. So the LANDSAT OLI data from October to January were utilized to map cotton crop. Using the typical signature of cotton crop, decision rules were prepared specific to each district and the cotton crop map over the five districts of Haryana has been prepared. The district was Sirsa, Fatehbad, Hissar, Jind and Bhiwani. The cotton area of these five districts covers more than $80 \%$ of the total cotton area of the state. The overall accuracy of the cotton crop classification was found to be more than $80 \%$.

Sugarcane is generally 10-12 month crop in Haryana. Sugarcane crop usually planted during June-July after the onset of monsoon or during December to January. Sugarcane is mainly grown in irrigated areas. Cloud free satellite data throughout the year were processed to classify sugarcane. If it is planted in January the representative temporal profile of sugarcane is also considered for mapping. The overall accuarcy of the sugarcane map was found to be more than $85 \%$.

\subsection{MODIS Net Primary Productivity (NPP) data as proxy to crop biomass}

Net Primary Productivity (NPP) defines the rate at which all plants in an ecosystem produce net useful chemical energy. In other words, NPP is equal to the difference between the rate at which plants in an ecosystem produce useful chemical energy (or GPP), and the rate at which they expend some of that energy for respiration. The MODIS NPP (MOD17; NASA) annual composite (at $1 \mathrm{~km} 2$ spatial resolution) has been chosen as a proxy parameter for biomass potential over agricultural area.

\subsection{Spatial downscaling of district level crop biomass residue}

The district level gross biomass of a crop was calculated using the crop statistics as discussed in the section 2.2. This district level gross crop biomass is disaggregated at $1 \mathrm{~km}$ grid level using a downscaling procedure as proposed below. The distribution of the district level gross biomass was done over those grids where the crop fraction exist. Further, the amount of biomass distributed to a particularly grid also depends not only on the fraction of the crop but also its contribution to the grid level aggregated crop biomass. So the crop wise weightage were calculated across the different fraction of the crop and the district level biomass was distributed accordingly. A detail description of the procedure is as follows;

\subsubsection{Generation of crop fraction of $1 \mathrm{~km}$ grid}

The crop masks of the selected crops were generated using multi-temporal satellite data. The sugarcane and cotton crop masks were generated at $30 \mathrm{~m}$ spatial resolution using LANDSAT OLI data. Whereas, wheat mask was generated at $56 \mathrm{~m}$ spatial resolution using AWiFS data. The rice mask was generated at $25 \mathrm{~m}$ resolution using RADARSAT-2 data. All these crop masks were resampled to $25 \mathrm{~m}$ spatial resolution and any overlapping due to misclassification were removed. Further, a fishnet of $1 \times 1 \mathrm{~km}$ grid size state was created over the Haryana state and the crop fractions of each of the selected crops were calculated. The crop fraction varied between zero in case of the absence of the crop to 1 if the grid is fully occupied by the concerned crop. So, on annual basis there are eight kinds of combinations were generated based on the cropping pattern of Haryana using the crop mask and LULC i.e. cotton fraction, sugarcane fraction, rice fraction, wheat fraction, rice-wheat fraction, cotton-wheat fraction, other crop fraction, unclassified fraction. The unclassified fraction mainly consist of fallow, urban area or water body which do not contribute significantly to the biomass i.e. NPP. This crop fraction images were further used in downscaling procedure.

\subsubsection{Generation of the crop specific weightage for downscaling}

To disaggregate the district level gross biomass to $1 \mathrm{~km}$ grid, we require the crop fraction and its specific weightage based on the biomass it could accumulate per unit area. As discussed earlier we have eight type crop combinations over Haryana state along with the grid wise NPP. If the contribution of individual crop at different crop fraction towards the NPP value is estimated, we could use it for downscaling. To estimate the weightages, we have used random forest algorithm using MATLAB software. Random forest (RF) is an ensemble learning technique developed by Breiman (2001) to improve the classification and regression trees (CART) method by combining a large set of decision trees. In random forest regression, each tree is built using a deterministic algorithm by selecting a random set of variables and a random sample from the training dataset (i.e. the calibration data set). Three parameters need to be optimized in RF: ntree, the number of regression trees grown based on a bootstrap sample of the observations (the default value is 500 trees); mtry, the number of different predictors tested at each node (the default value is $1 / 3$ of the total number of the variables) and; nodesize, the minimal size of the terminal nodes of the trees (the default value is one). Random forest creates many sub samples of the input dataset. These sub samples are selected randomly with replacement. For example if input data has a dimension $1000 * 25$ then 500 sub samples, each of size 
$750 * 25$ may be created. Each of these sub samples are referred as a tree and trained independently. Finally, their predictions are combined through averaging (in case of regression problem) or by majority vote (in case of classification) to make the final prediction.

In a given tree, not all the features of the input dataset are used while making the prediction. Each tree uses $\mathrm{N} 1<\mathrm{N}$ (N is the number of features in the input dataset) features to make the prediction. Such randomness in feature selection decreases the correlation between different trees which improves the overall accuracy in estimation. Prediction is made by a set of decision rules derived from data partitioning. Data partitioning is made is done in such a way that it maximizes the overall information gain or the Gini gain over the data.

There are two important parameters that have to be defined while building the model (1) Number of trees and (2) Number of features to be used in each tree. In this study 500 trees and 3 features (in each tree) were used to design the model. Other parameters like minimum leaf size, type of predictor to use in each region of the tree are set as default value. Random Forest is deployed to obtain the response curve of NPP against the crop fraction of rice, wheat, cotton and sugarcane. Input data consists of 8 independent variables (rice fraction, wheat fraction, cotton fraction, sugarcane fraction, rice-wheat fraction, cotton-wheat fraction, other crop fraction and unclassified fraction) and 1 dependent variable (NPP) for 68061 unique locations (grids) of Haryana. Model was trained on 42500 data points and tested on17561 data points. Training data and test data produces an $\mathrm{R}^{2}$ of 0.92 and 0.87 respectively. It can be inferred that our model is both accurate and generalizable and hence it can be used for further analysis. Hence calibration curve for each selected crop has been prepared which denote contribution of crop fraction towards NPP. This calibration curve was further used to downscale the gross bioenergy.

\subsubsection{Disaggregation of the district level gross biomass to 1 km grid}

The spatial downscaling of the gross biomass from crop residue is demonstrated as follow:

$$
\mathrm{BE}_{i, j, k}=\left(\mathrm{NPP}_{i, j, k} \cdot \overline{\mathrm{NPP}}_{k}^{-1}\right) \cdot \mathrm{BE}_{k} \cdot n_{k}^{-1}
$$

Where $\mathrm{BE}_{\mathrm{i}, \mathrm{j}, \mathrm{k}}$ indicates gross biomass from crop residue of pixel $\mathrm{i}, \mathrm{j}$ within district $\mathrm{k}$ in Haryana; $\mathrm{NPP}_{\mathrm{i}, \mathrm{j}, \mathrm{k}}$ is the net primary productivity of a $1 \mathrm{~km}^{2}$ spatial resolution pixel $\mathrm{i}, \mathrm{j}$ in district $\mathrm{k}$; $\overline{N P P}_{\mathrm{k}}$ is the average net primary productivity of a specific crop for each pixel in district $\mathrm{k} ; \mathrm{BE}_{\mathrm{k}}$ is the total gross biomass from crop residue in district $\mathrm{k}$, and $\mathrm{n}_{\mathrm{k}}$ was the amount of pixels in district $\mathrm{k}$.

\section{Results \& Discussions:}

The present study aims to generating spatial map of bioenergy potential from selected crop residues over Haryana state. Towards this objective, first district level aggregated gross residue potential from the selected crops have been calculated using the crop production statistics. District wise crop production data was multiplied with the residue production ratio to calculate the gross residue production from the crop at district level. Further, crop map of rice wheat, cotton and sugarcane were generated using multi- temporal satellite. The crop fraction at $1 \mathrm{~km}$ grid was calculated using these crop masks. MODIS NPP was analyzed and NPP at $1 \mathrm{~km}$ grid was resampled accordingly. The contribution of different crop fractions towards the NPP were calculated using random forest algorithm. These were further used a weightage of the each crop in disaggregating the district level gross residue potential at $1 \mathrm{~km}$ grid. Further, disaggregated gross residue potential of a crop was further converted into surplus residue potential using the surplus coefficient. The surplus residue potential was converted into bioenergy potential using the calorific values of the selected residues. The detail discussion on the above mentioned procedure is provided in the following sections.

\subsection{District wise gross residue potential of the selected crops}

The district wise crop production statistics of rice, wheat, cotton and sugarcane crops over Haryana state was obtained from Directorate of economics and statistics, Govt of India. The crop production statistics of last five years (2011-16) was collected and the average value of the crop production at district level was taken for calculation of the gross residue potential of the crop. The residue production ratio of the selected crop are mentioned in the Table 3.1 following the Hiloidhari et. al., 2014. District gross residue potential (in million tonnes on dry weight basis) was calculate for rice, wheat, cotton and sugarcane crop and presented in Fig 3.1.

Table 3.1 Crop wise residue production ratio and heating value used in the present study

\begin{tabular}{|l|l|l|l|}
\hline Crop & Residue & $\begin{array}{l}\text { Residue } \\
\text { production } \\
\text { ratio }\end{array}$ & $\begin{array}{l}\text { Heating } \\
\text { value } \\
(\mathrm{MJ} / \mathrm{kg})\end{array}$ \\
\hline \multirow{2}{*}{ Rice } & Straw & 1.5 & 15.54 \\
\cline { 2 - 4 } & Husk & 0.2 & 15.54 \\
\hline \multirow{3}{*}{ Wheat } & Straw & 1.5 & 17.15 \\
\cline { 2 - 4 } & Husk & 0.3 & 17.39 \\
\hline \multirow{3}{*}{ Cotton } & Stalk & 3.8 & 17.4 \\
\cline { 2 - 4 } & Husk & 1.1 & 16.7 \\
\cline { 2 - 4 } & Boll shell & 1.1 & 18.3 \\
\hline \multirow{2}{*}{ Sugarcane } & Bagasse & 0.33 & 20 \\
\cline { 2 - 4 } & Top \& leaves & 0.05 & 20 \\
\hline
\end{tabular}

It is observed that the gross residue potential of rice crop vary greatly across the Haryana state (Fig. 3.1). The gross residue potential is found to be very high over Karnal (1.08 MT), Kaithal (0.96 MT) and Kurukshetra (0.9 MT) as these the predominantly rice growing areas. Moderate amount of gross residue potential from rice crop was observed over Fatehbad (0.73 MT), Jind (0.63 MT), Panipat (0.4 MT), Sonipat (0.45 MT), Yamuna Nagar (0.54 Mt), Ambala (0.64 MT) and Sirsa (0.4 MT). Low gross residue potential of rice crop was found over Bhiwani (0.08 MT), Hisar (0.23 MT), Rohtak (0.15 MT), Gurgaon (0.07 MT), Faridabad (0.23 MT), Jhajjar (0.14 MT), Rewar (0.02 MT) Panchkula (0.06 MT) and Mahendragarh. It is important to mention here that the gross residue potential of district depends on the total rice growing area of the district and its productivity or yield or vigour of the crop.

The gross residue potential of wheat crop was found to be relatively higher than the rice crop as the production of wheat is also more than the rice (Fig. 3.1). Highest gross residue potential of wheat crop was found Sirsa (2.22 MT) followed by Fatehbad (1.4 MT), Hissar (1.57 MT), Jind (1.48 MT), Kaithal (1.3 MT), Karnal (1.25 MT) and Sonipat (1.1 MT), Bhiwani (1 MT), Gurgaon (0.8 MT), Faridabad (0.9 MT). Moderate amount of gross residue potential from wheat crop was found over Ambala (0.54 MT), Yamunanagar (0.69 MT), Kurukshetra 
(0.812 MT), Panipat (0.63 MT), Rohtak (0.66 MT), Jhajjar (0.63 MT). Low amount of gross residue potential of wheat crop was found over Panchkula (0.08 MT), Mahendragarh (0.3 MT), $\operatorname{Rewar}(0.35 \mathrm{MT})$

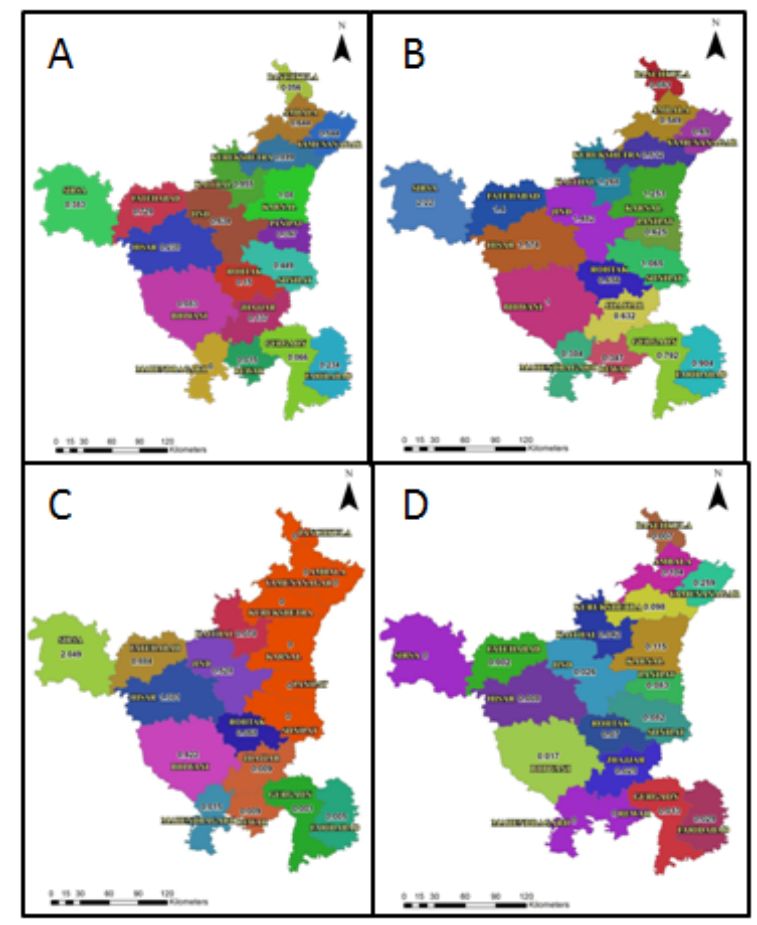

Fig. 3.1 District wise gross residue potential (MT) from (A) rice, (B) wheat (C) cotton, (D) sugarcane over Haryana

Cotton crop is mainly grown in the western part of Haryana (Fig. 3.1). This part of Haryana is comparatively dry from the rest of the areas. Cotton being deep rooted crop could withstand dryness to some extent. The Sirsa was found to have highest gross residue potential from cotton i.e. (2.05 MT), followed by Hisar (1.3 MT), Fatehbad (0.89 MT), Jind (0.53 MT) and Bhiwani (042 MT). Rest of the district poses very minimal gross residue potential from cotton

Sugarcane crop is mainly grown in the north-eastern districts of Haryana state. It is grown in the irrigated belts as a crop of nearly one year. The gross residue potential of sugarcane was found to be highest over Yamunanagar ( $0.26 \mathrm{MT})$ followed by Karnal (0.12 MT), Ambala (0.11 MT) and Kurukshetra (0.10 MT). Rest of the district showed very low gross residue potential of sugarcane crop. In the present study, the sugarcane crop mapping was also conducted over these four districts to cover major sugarcane growing regions of Haryana state.

\subsection{Crop specific weightage towards grid level NPP}

In the present study, four dominating crops over Haryana were selected and mapped using satellite data. Further these crop masks were converted into crop fractions at $1 \mathrm{~km}$ grid level. Thus it gave rise four images of crop fractions. Apart from these, using the crop mask and based on the cropping pattern grid images of Rice crop only, wheat crop only, Rice-wheat only, Cotton crop only, Cotton -wheat only, Sugarcane only were generated. These grid images are considered as independent variable and relate with the NPP images as dependent variable. Random Forest Algorithm was used to find out the relationship between the crop fraction and its contribution to NPP. As NPP is considered to be a proxy of the above ground biomass, It could be considered an auxiliary parameter to downscale the district level gross residue potential of the crop.

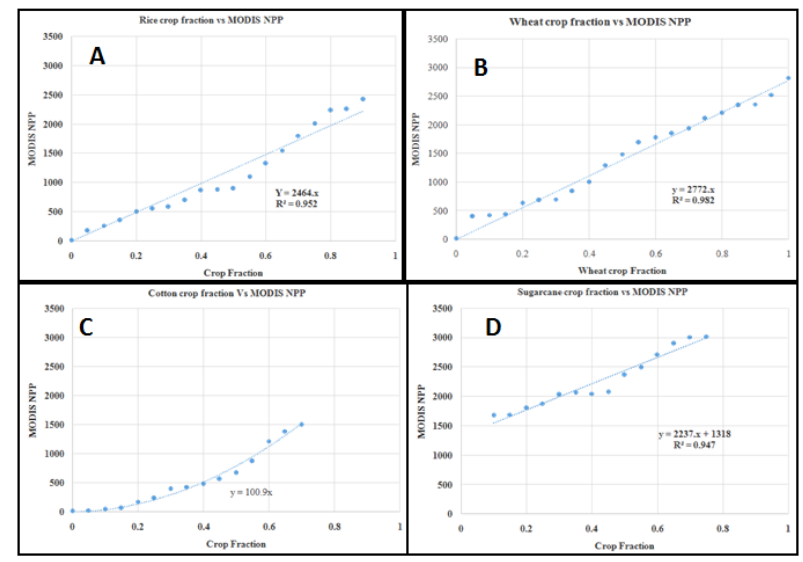

Fig. 3.2 Contribution of different crop fraction towards MODIS (A) rice, $(B)$ wheat $(C)$ cotton, $(D)$ sugarcane

The contributions of different crop fractions to the MODIS NPP are presented in Fig. 3.2. It is observed that the contribution of rice crop fraction is linear and it could contribute to MODIS $\mathrm{NPP}$ as high as $\sim 2500 \mathrm{kgC} \mathrm{m}^{-2}$. The slope of the curve is 2464 comparative less than the wheat i.e. 2772 (Fig. 3.2). The contribution of wheat crop fraction is also found to be linear and it can contribute to the MODIS NPP as high as $2700 \mathrm{kgC} \mathrm{m}^{-2}$. The yield and production of the wheat crop was found to be significantly higher than the rice crop over Haryana. Similarly the contribution of wheat to the MODIS NPP was found to be higher than the rice fraction across any crop fraction, corroborating with the yield and biomass production statistics of the crops. The relationship between the cotton crop fraction and MODIS NPP was found to be curvi-linear and the maximum contribution of the cotton crop fraction to MODIS NPP was found to be nearly $1500 \mathrm{kgC} \mathrm{m}^{-2}$ significantly less than wheat and rice crop. The cotton crop is grown at a spacing of 80-100 $\mathrm{m}$, so the plant per unit area is less causing low value of the Leaf Area Index (LAI) unlike rice and wheat crop. The sugarcane produce highest biomass and thus contributed highest value to the MODIS NPP i.e. $3000 \mathrm{kgC} \mathrm{m}^{-2}$ at crop fraction of $0.7-0.8$. It is apt to mention here that sugarcane crop fraction more than 0.8 was not available in the dataset. In nutshell, the contribution of the cotton crop fraction, comparatively, was found to the lowest, followed by the rice crop fraction and wheat crop fraction. The highest contribution was observed in case of sugarcane crop towards the MODIS NPP. This relationship between the crop fraction and MODIS NPP was used further as a crop specific weight to downscale the district level gross residue potential from the crop concerned.

\subsection{Disaggregation of gross residue potential}

Using the weightage of the crop the district level gross residue potential of crop has been disaggregated to the $1 \mathrm{~km}$ grid level using the procedure as mentioned in the section 2.5.4. The district level gross residue potential was distributed over the different grids of the district, based on the crop fraction and its associated weightage. Hence, the grid which is having higher fraction of the concerned crop, will be distributed more biomass than the grid with low crop fraction. At the same time, 
distribution of the biomass would be different for different crops for the same crop fraction as explained in section 3.2.

The gross residue potential of a crop refers to the amount of residue potential available from a crop after it is being harvested or processed during post-harvest. But the whole amount may not be available for bioenergy, as it is been used for domestic fuel, cattle feed, thatching or other uses. A surplus coefficient has been derived by a questionnaire survey over the state. These crop specific surplus coefficient were used to convert the gross residue potential into surplus residue potential. The surplus coefficients used in the present study have been taken from Hiloidhari et al., 2014. The surplus coefficient of rice and wheat was considered to be $34 \%$, for cotton $90 \%$ and for sugarcane $40 \%$.

To assess the amount of energy that could be obtained from different crop residue, heating values or the calorific value were used in the present study. The heating values of the concerned residue are presented in Table 3.1. The surplus residue potential was multiplied with the heating value of the concerned crop to obtained bioenergy potential of the crop. The spatial map of the bioenergy potential of the rice, wheat, cotton and sugarcane crop over Haryana state are presented in Fig. 3.3.

Table: 3.2 Heating values (Calorific values) of different crop residues

\begin{tabular}{|l|l|l|}
\hline Crop & Residue & $\begin{array}{l}\text { Heating value } \\
(\mathrm{MJ} / \mathrm{kg})\end{array}$ \\
\hline \multirow{2}{*}{ Rice } & Straw & 15.54 \\
\cline { 2 - 3 } & Husk & 15.54 \\
\hline \multirow{3}{*}{ Wheat } & Straw & 17.15 \\
\cline { 2 - 3 } & Pod/Husk & 17.39 \\
\hline \multirow{3}{*}{ Sugarcane } & Stalk & 17.4 \\
\cline { 2 - 3 } & Husk & 16.7 \\
\cline { 2 - 3 } & Boll shell & 18.3 \\
\cline { 2 - 3 } & Bagasse & 20 \\
\cline { 2 - 3 } & Tops and Leaves & 20 \\
\hline
\end{tabular}

The rice residue is having the least heating value $(15.54 \mathrm{MJ} / \mathrm{kg})$. So the bioenergy potential from the same crop fraction was found to be the lowest. But the availability of the rice crop residue was found to very high particularly over the Kaithal, Karnal, Kurukshetra districts. Similarly grids with high amount bioenergy potential $(0.20 \mathrm{GJ})$ were found over these districts. Grids with moderate amount of bioenergy potential (0.10 MJ) were also found in and round of the district as mentioned above. The heating value of the wheat crop residue was considered to be $17.20 \mathrm{MJ} / \mathrm{kg}$ which is higher than the rice residue. Hence, the bioenergy potential from wheat crop residue was found to be higher across the state. Grids with high bioenergy potential (0.70 GJ) were observed over Sirsa, Fatehbad, Hisar, Jind, Kaithal, and Karnal. The heating value of the cotton crop residue was considered to be $17.2 \mathrm{MJ} / \mathrm{kg}$. As majority of the cotton crop parts are left in the field, nearly $90 \%$ of the total cotton biomass becomes surplus. Hence the bioenergy potential from surplus cotton crop was found to be high compared to wheat and rice crop. Grids with high bioenergy potential (2.5 GJ) were found to be distributed over Sirsa and parts of Hisar and Fatehbad.

The heating value of the sugarcane crop was considered to be $(20 \mathrm{MJ} / \mathrm{kg})$, highest among the other selected crop. But the sugarcane fraction in the study area was found to be very less. So the bioenergy potential from sugarcane crop residue was found to be in the lower side. Grids with high bioenergy potential $(0.20 \mathrm{GJ})$ were distributed over the Yamunanagar district.

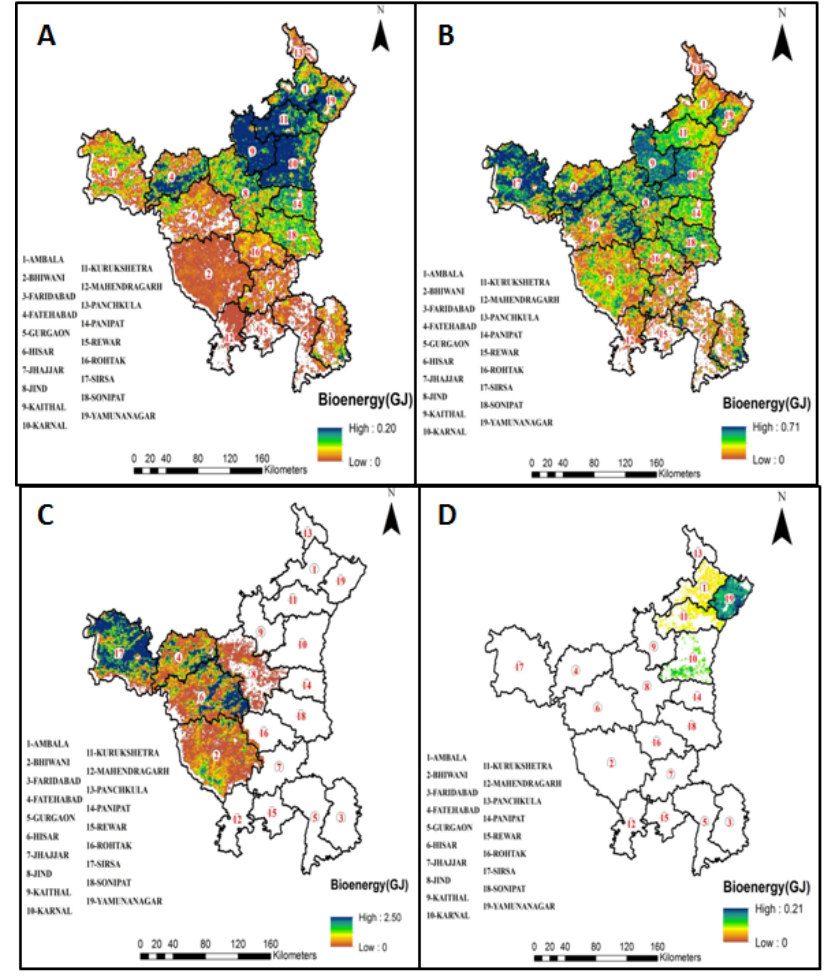

Fig. 3.3 Disaggregated bioenergy potential (GJ) of surplus residue potential of (A) Rice, (B) Wheat, (C) Cotton, (D) Sugarcane crop over Haryana

\section{Conclusions}

The present study assessed the surplus residue potential from selected four crops over Haryana at district level. Further it was disaggregated at $1 \mathrm{~km}$ grid level using NPP as an auxiliary variable to produce spatial map of biomass/bioenergy potential from surplus crop residue. Haryana being mainly agrarian society, large amount of crop are produced across that state and as a spin off product large amount of surplus biomass residue is generated. These residues are often burned to clear the field on time to catch the next crop season. This practice is very common in Haryana and causes lot of pollution in the state and the adjoining areas. Govt. of India imposed many laws and restrictions to stop the biomass burning but could not able to stop it. The only option left to stop this nuisance to incentivise the utilization of this surplus biomass. Hence, it should be diverted to produce energy from the biomass economically. So, a meticulous planning is required to establish the bio-fuel plants to utilize it optimally. The most important information in this respect is to assess the kind of biomass available in and round the plant along with its quantity. The spatial map of the surplus biomass of the major crops grown in Haryana will cater this information and a spatial information system could be generated along with other thematic later such as LULC, road network, water bodies availability etc and a spatial query based suitability study could be made using these type of geospatial product. This will further, strengthen the vision to promote and utilization of the renewable sources of energy. 


\section{References:}

Biomass Atlas V2.0. 2004. Biomass Resource Atlas of India. http://lab.cgpl.iisc.ernet.in/Atlas/ (accessed October 2018).

Directorate of economics and statistices , 2016. (https://eands.dacnet.nic.in/)

Hiloidhari, M. and Baruah, D.C., 2011a. Crop residue biomass for decentralized electrical power generation in rural areas (part 1): Investigation of spatial availability. Renewable and Sustainable Energy Reviews, 15, pp. 1885-92.

Hiloidhari, M. and Baruah, D,C., 2011b Rice straw residue biomass potential for decentralized electricity generation: A GIS based study in Lakhimpur district of Assam, India. Energy for Sustainable Development, 15, pp. 214-22.
Hiloidhari, M., Das, D., Baruah, D.C., 2014. Bioenergy Potential from Crop residue biomass in India. Journal on Renewable and Sustainable Energy Reviews, 32, pp. 504-512.

India: Biomass for Sustainable Development-Lessons for Decentralized Energy Delivery Village Energy Security Programme. Document of the World Bank. 2011. http:// http://www.mnre.gov.in/pdf/VESP-Final-ReportJuly\%202011.pdf [2].

Kumar, U. and Jain, V.K., 2010. Time series models (GreyMarkov, Grey Model with rolling mechanism and singular spectrum analysis) to forecast energy consumption in India. Energy, 35, pp. 1709-1716.

WORLD Energy Resources - Bioenergy /2016 Report on World Energy Council. 